\title{
Antidementiva: Stellenwert, Wirksamkeit und Grenzen
}

Daniel Kopf, Lutz Frölich

\section{Erratum}

In Tabelle 2 sowie im Kapitelteil „Verträglichkeit von Memantin“ (PDF: S. 12) und in den Kernaussagen (PDF: S. 14) muss es korrekt heißen „Memantin ist zugelassen bei moderater bis schwerer Alzheimer-Demenz“.

Die Zulassung von Memantin wurde auf die „moderate bis schwere Alzheimer-Demenz" ausgeweitet, sodass bereits Patienten mit einem Mini-Mental-State-Test von 20 oder weniger Punkten behandelt werden dürfen.

Der Verlag entschuldigt sich für dieses Versehen. 